Canadian Studies in Population 42, no. 1-2 (2015): 130-148.

\title{
A parametric model for estimating nuptiality patterns in modern populations
}

\author{
Paraskevi Peristera ${ }^{1}$ \\ Anastasia Kostaki
}

\begin{abstract}
Nuptiality is a phenomenon closely related to fertility. The age-specific marriage distribution has a typical shape common in all human populations. In order to estimate this pattern, alternative parametric models have been proposed. However recent evidence suggests that mixture models are required to estimate nuptiality patterns. In this paper, a flexible parametric model is proposed in three versions, appropriate to describe the age pattern of first marriage rates. For evaluation purposes the models as well as the alternative existing models are fitted to a variety of empirical datasets.
\end{abstract}

Keywords: nuptiality pattern, parametric modelling, mixture modelling, nonlinear estimation, heterogeneity.

\section{Résumé}

La nuptialité est un phénomène étroitement lié à la fertilité. La répartition selon l'âge des mariages est habituellement semblable pour toutes les populations humaines. Afin d'évaluer ce modèle, d'autres modèles paramétriques ont été suggérés. Cependant, de récentes données probantes indiquent qu'un mélange de modèles est nécessaire pour évaluer les modèles de nuptialité. Cet article propose un modèle paramétrique en trois versions, convenant pour décrire le modèle d'âge des taux du premier mariage. À des fins d'évaluation, les modèles et les alternatifs existants sont adaptés à des ensembles de données empiriques.

Mots-clés : modèle de nuptialité, modèle paramétrique, modélisation mixte, estimation non linéaire, hétérogénéité.

\section{Introduction}

Analysis of the age pattern of nuptiality is of great importance for demographers. Parametric models that describe the age pattern of first marriages are valuable tools in demographic research, as they can also be used for indirect estimations of fertility, as well as for projection purposes.

The Coale (1971) and the Coale-McNeil (1972) models are classical tools widely used for describing nuptiality patterns (Bloom 1982; Bloom and Bennett 1990; Goldstein and Kenney 2001). Various studies (Bloom 1980; Casterline and Trussell 1980; Hobcraft and Trussell 1980; Trussell and Bloom

1. Stress Research Institute, Stockholm University (Sweden). Corresponding author: Anastasia Kostaki,

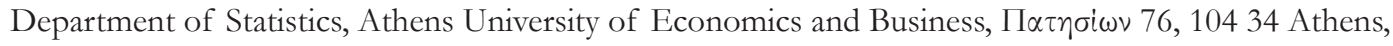
Greece. Email: kostaki@aueb.gr. 
Peristera and Kostaki: A parametric model for estimating nuptiality patterns in modern populations

1981; Trussell et al. 1981) have investigated the accuracy of these models in describing nuptiality. However, recent studies (Kaneko 2003, 2005) argue that country-specific nuptiality standards are often required, since the global standard schedule — derived from Swedish data—-might be inappropriate for some populations. It is crucial to identify the country-specific shape of nuptiality schedules when one is interested in predicting fertility by birth order. To this end, Kaneko $(2003,2005)$ suggested the use of the Generalized Log Gamma model (GLG), which is an improved adjusted version mathematically identical to the Coale-McNeil model, to describe the age pattern of first marriages and of births.

However, in recent years considerable variation has been observed in the pattern of marriages using datasets of populations from several countries. Liang (2000) observed that in Chinese data a bulge was apparent at the early ages of the first marriages distribution. The new pattern of agespecific marriage curves reflects heterogeneity in behaviour concerning first marriages. Liang (2000) made the plausible hypothesis that marriages may come from two different groups. This heterogeneity may be associated with many factors such as educational level, social status, and religion. Thus population groups exist with different demographic characteristics regarding marriage, which can be further explored if appropriate data are available.

The purpose of this paper is to present and evaluate a flexible parametric model in three versions, in order to capture both the classical and the new shape of first marriage rates in modern populations. This model was initially proposed by the authors for describing fertility schedules (Peristera and Kostaki 2007), showing a very successful performance when fitted to empirical fertility rates, and proved superior to other models previously proposed for describing fertility. A significant advantage of the model, besides its capacity to successfully describe both fertility and nuptiality patterns, is that summarizing the characteristics of the two curves into a limited set of parameter values allows comparisons of the two patterns in a population.

In order to evaluate the adequacy of the model, we fit it and the existing ones into first marriage rates for several male and female populations.

The next section is devoted to a presentation of existing models for fitting first marriage rates. In Section 3 the three versions of the model are presented, while Section 4 presents the results of fitting the alternative models to empirical first marriage rates. Some concluding remarks are given in the final section.

\section{A review of parametric nuptiality models}

Coale (1971) was the first to observe that age distributions of first marriages are structurally similar in various populations. These distributions tend to be smooth, unimodal, skewed to the right, and have a density close to zero below age 15 and above age 50. In addition, he observed that first marriage rates across female populations exhibit differences in their peaks, spread, and their cumulative values at older ages.

Moreover, Coale (1971) showed that the age pattern of first marriage rates was virtually identical in populations characterized by widely different marriage customs, upon adjusting the vertical and horizontal scales and the origin of the distribution of first marriage frequencies. In addition, as a basis for the utilization of these observations, Coale prepared a standard schedule of first marriage frequencies, using data from Sweden, covering the period 1865-69. Coale and McNeil (1972) subsequently developed a closed-form expression that closely replicates the reference distribution presented by Coale (1971), as

$$
g_{s}(x)=0.1946 \exp \{-0.174(x-6.06)-\exp [-0.2881(x-6.06)]\}
$$


This model, known as the Coale-McNeil standard schedule, can be related to any observed distribution by adjusting its location, dispersion, and cumulative values.

Consequently, the distribution of first marriage rates at a given age $a$, in any observed population, is given by

$$
g(a)=\frac{C}{k} g_{s}\left(\frac{a-a_{0}}{k}\right)
$$

where $C$ denotes the proportion eventually marrying in the population, $a_{0}$ is the origin of the observed distribution or equivalently the youngest age at which an appreciable number of first marriages occurs, which approximately is the first percentile of the distribution; and the parameter $k$ is the inverse of the rate at which first marriages occur in the target population relative to the Swedish standard. Furthermore, $k$ is proportional to the standard deviation of the frequency distribution of observed first marriages.

As an alternative to eq(1), Rodriguez and Trussell (1980) have proposed the following model,

$$
g(a)=\frac{E}{\sigma} 1.2813 \exp \left\{-1.145\left(\frac{a-\mu}{\sigma}+0.805\right)-\exp \left[-1.896\left(\frac{a-\mu}{\sigma}+0.805\right)\right]\right\},
$$

where $\mu, \sigma$, and $E$ are the mean, standard deviation of age at first marriage, and proportion ever marrying, respectively.

In a more general sense, Coale-McNeil define the probability density function (PDF) for the age distribution of first marriages as

$$
g(x)=\frac{\beta}{\Gamma(a / \beta)} \exp [-a(x-\mu-\exp \{-\beta(x-\mu)\})],
$$

where $\Gamma$ denotes the gamma function, while $a>0, \beta>0$, and $-\infty<\mu<\infty$ are parameters to be estimated. An interesting feature of the Coale-McNeil distribution is that it is a limiting probability distribution of convolution for an infinite set of mean-related exponential distributions. Thus it is regarded as a convolution of distribution of its own form and some related exponential distributions as well. This structure provides a mathematical model for a multi-stage process, i.e., a process that consists of multiple processes required for the target event to happen. Coale and McNeil (1972), following Feeney (1972), viewed first marriage as a multi-stage process in which entry into marriageable stage, meeting of the eventual spouse, and engagement are required to take place prior to the marriage.

The Coale-McNeil distribution given by eq(4) is mathematically identical to the generalized log gamma distribution, with a somewhat different parameter space (Kaneko 1991, 2003). According to Prentice's parameterization (1974), the Coale-McNeil distribution is expressed in PDF form of the GLG distribution by

$$
g(x)=\frac{|\lambda|}{b \Gamma\left(\lambda^{-2}\right)}\left(\lambda^{-2}\right)^{\lambda^{-2}} \exp \left[\lambda^{-1}\left(\frac{x-\mu}{b}\right)-\lambda^{-2} \exp \left\{\lambda\left(\frac{x-\mu}{b}\right)\right\}\right]
$$

where $\lambda(-\infty<\lambda<0), \mu(-\infty<\mu<\infty)$, and $b(>0)$ are the three parameters to be estimated and $\Gamma$ denotes the gamma function. Then the corresponding age schedule $f(x)$, i.e., the age-specific first marriage rate at age $x$, is given by

$$
f(x ; C, \mu, b, \lambda)=C \cdot g(x ; \mu, b, \lambda),
$$

where $C$ denotes the proportion eventually being married. 
The standard Coale-McNeil model is widely used in the literature for representing age-specific first marriage rates, and it is generally accepted that it provides good fits. It is also pointed out that the standard Coale-McNeil model performs well because it is based on marriage rates of an actual population. Bloom and Bennett (1990) mention that even when the true model generating a given distribution of marriage rates is unknown, the standard Coale-McNeil model may fit well, and even better than a purely theoretical model, such as that of Hernes (1972), or a purely ad hoc empirical model such as that of Keeley (1979). This happens because the true model is captured implicitly in the rates on which the standard Coale-McNeil model is based.

However, recently many studies point out that the estimated rates using the Coale-McNeil model bear substantial deviations from observed schedules, even in its maximally flexible free-shape form, especially when it is applied to non-European population data, such as Japan (Takahashi 1979; Kojima 1985; Kaneko 1991). Regarding the performance of the generalized log gamma model (identical to the Coale-McNeil one), it is generally accepted that it is good. Nevertheless as Kaneko (1991, 2003) pointed out, for cohorts of some countries, e.g., Japan, it shows visible discrepancies even when allowing a free-shape (4-parameter) model. Liang (2000) also points out that the standard Coale-McNeil model and the corresponding one proposed by Rodriguez and Trussell (1980) cannot be applied in countries like India and China, where marriage patterns are different from those in Western countries. However in the case of Indian and Chinese data, the Coale-McNeil fits well when restrictions of the parameters were released (Liang 2000).

The models described so far do not capture a marriage pattern that appears in some modern populations, in which a second peak arises at younger ages. Therefore, new representations are required in order to describe the distorted patterns. For that, Liang (2000), based on an idea of Chandola et al. (1999), built a mixture model using the double-exponential distribution denoted as the Coale-McNeil mixture model. This model is described by the following equation:

$$
\begin{aligned}
f\left(x ; m, \alpha_{1}, \lambda_{1}, \mu_{1}, \alpha_{2}, \lambda_{2}, \mu_{2}\right)= & \frac{m \lambda_{1}}{\Gamma\left(\frac{\alpha_{1}}{\lambda_{1}}\right)} \exp \left(-\alpha_{1}\left(x-\mu_{1}\right)-e^{-\lambda_{1}\left(x-\mu_{1}\right)}\right) \\
+ & +\frac{(1-m) \lambda_{2}}{\Gamma\left(\frac{\alpha_{2}}{\lambda_{2}}\right)} \exp \left(-\alpha_{2}\left(x-\mu_{2}\right)-e^{-\lambda_{2}\left(x-\mu_{2}\right)}\right),
\end{aligned}
$$

where $m$ is the mixture parameter that determines the relative size of the group of women who marry earlier.

\section{The model}

In this paper we propose three versions of a parametric model for fitting the age-specific distributions of marriages.

The simple version (hereafter Model) is defined by

$$
f(x)=c_{1} \cdot \exp \left[-\left(\frac{x-\mu}{\sigma(x)}\right)^{2}\right]
$$

where $f(x)$ is the age-specific first marriage rate at age $x^{1} ; \sigma(x)=\sigma_{11}$ if $x<=\mu$ and $\sigma(x)=\sigma_{12}$ if $x>\mu$; and $c_{1}, \mu, \sigma_{11}$, and $\sigma_{12}$ are parameters to be estimated. The parameter $c_{1}$ is related to the base level of the 
distribution and $\mu$ reflects the location of the distribution, while $\sigma_{11}$ and $\sigma_{12}$ reflect the spread of the distribution before and after its peak, respectively.

Then, based on the idea of Chandola et al. (1999) and Liang (2000), we propose two mixture versions of eq(8), with two additive terms in order to capture the new distorted shape of nuptiality curve. This first mixture version (hereafter denoted as Mixture Model 1) is given by the formula

$$
f(x)=c_{1} \cdot \exp \left[\left(\frac{x-\mu_{1}}{\sigma_{1}}\right)^{2}\right]+c_{2} \cdot \exp \left[-\left(\frac{x-\mu_{2}}{\sigma_{2}}\right)^{2}\right],
$$

where $f(x)$ is the age-specific first marriage rate at age $x$, and $c_{1}, c_{2}, \mu_{1}, \mu_{2}, \sigma_{1}$, and $\sigma_{2}$ are parameters to be estimated.

The parameters $c_{1}$ and $c_{2}$ are related to the base level of the first and second hump, respectively; $\mu_{1}$ and $\mu_{2}$ reflect the location of the first and the second hump, respectively, and are related to the mean ages of the two subpopulations, the one that gets married earlier and the second that marries at later ages; and $\sigma_{1}$ and $\sigma_{2}$ reflect the spread of the two humps.

In some datasets, the highest peak of the curve is steeper in the left part. This feature led us to make an adjustment to Mixture Model 1, allowing an extra parameter to be imposed in the first term of the model. The second mixture version of the model (hereafter Mixture Model 2) thus becomes

$$
f(x)=c_{1} \cdot \exp \left[-\left(\frac{x-\mu_{1}}{\sigma_{1}(x)}\right)^{2}\right]+c_{2} \cdot \exp \left[-\left(\frac{x-\mu_{2}}{\sigma_{2}}\right)^{2}\right],
$$

where $\sigma_{1}(x)=\sigma_{11}$ if $x<=\mu_{1}$ and $\sigma_{1}(x)=\sigma_{12}$ if $x>\mu_{1}$.

The parameters have the same meaning as in Mixture Model 1, while $\sigma_{11}$ and $\sigma_{12}$ reflect the spread of the main hump of the curve before and after its peak, respectively.

\section{Model evaluation and comparisons}

For evaluation purposes the three versions of the proposed model, as well as the Standard CoaleMcNeil and the Coale-McNeil four-parameter models, the GLG one, and the Coale-McNeil mixture model are fitted to various empirical datasets. Initially, we compare our basic model with the Standard Coale-McNeil one, the Coale-McNeil four-parameter one, and the GLG model. Then, in cases where these models fail to adequately estimate the nuptiality pattern, the Coale-McNeil mixture model and the two mixture versions of our model (Mixture Model 1 and Mixture Model 2) are fitted.

In the literature, it has been long discussed whether a period or a cohort approach should be adopted in the study of fertility and nuptiality. The advantages and disadvantages of both approaches have been repeatedly pointed out. It is accepted that period measures of nuptiality and fertility are subject to compositional and distributional distortions, such as those from flux in marital and parity composition and tempo effects (Kaneko 2003). Though suggestions have been made for correcting the distortions of the period measures (Bongaarts and Feeney 1998; Kohler and Philipov 2001; Kohler and Ortega 2002; and Ryder 1964, 1980), cohort nuptiality measures, which are free from these effects, are of primary importance. However cohort measures have the disadvantage that they cannot be calculated until the life course process of the events is completed, and therefore they do not provide information on the current situation of uncompleted phenomena.

Thus, our applications are based on period data. This is justified for two reasons. Firstly, the period approach enables us to examine and evaluate recent developments in demographic events and 
Peristera and Kostaki: A parametric model for estimating nuptiality patterns in modern populations

also perform a comparative analysis of them, while the cohort approach is by definition concerned with longer-term development, as cohort trends and differences are accumulated during relatively long periods of time. Secondly, period data are readily available for analytical purposes, whereas cohort data frequently remain incomplete and difficult to reconstruct.

Therefore, period single-year age-specific first marriage rates for female and male populations of Spain, the Netherlands, Norway, Sweden, Finland, the UK, and Ireland are used for existing available years. The empirical data were obtained from the Eurostat New Cronos database.

Regarding estimation of the parameters of the various models, it is generally accepted that for graduation purposes, where it is important to bring out the structure of the underlying 'true' curves by removing the effects of random variations, weighted least squares - with weights equal to the reciprocals of the estimated variances of the ungraduated rates - is the most efficient curve fitting procedure, especially if the models refer to mortality (Hoem 1976). Therefore, in our evaluations we first have fitted the models using weighted non-linear least squares, minimizing the following sum of squares:

$$
\sum_{x} w_{x}\left(\hat{f}_{x}-f_{x}\right)^{2},
$$

with weights $w_{x}$ as the reciprocals of the estimated variances of the age-specific marriage rates $w_{x}=E_{x}$ $w / f_{x} \cdot\left(1-f_{x}\right)$, where $E_{x}$ is the exposed-to-risk population at age $x$ and $f_{x}$ is the marriage rate at age $x$. However, our calculations using the weighted approach showed only marginal improvement of the fit of the model compared to the unweighted one. Hoem et al. (1981) also suggest an unweighted approach for fitting fertility rates of modern populations. Thus, the parameters of the model have been estimated by means of a non-weighted non-linear least-squares procedure, by minimizing the following sum of squares:

$$
\sum_{x}\left(\hat{f}_{x}-f_{x}\right)^{2}
$$

where $\hat{f}_{x}$ is the estimated marriage rate at age $x$ and $f_{x}$ is the corresponding empirical one.

All functions are fitted by means of a non-linear least-squares procedure and a Gauss-Newton optimization scheme. Matlab's built-in Isqnonlin routine for non-linear parameter estimation was used in order to find the unconstrained minimum of the minimizing criterion eq(12).

The results of our analyses are provided in the Appendix. The estimated values of model parameters for the female and male populations of the seven countries presented in this work are given in Tables 1 to 4 . The corresponding residual sums of squares are given in Table 5. Furthermore, the empirical and fitted age-specific marriage rates for selected cases are illustrated in Figures 1 to 6.

Initially we fit the simple models, and therefore compare the standard Coale-McNeil model, the GLG model, the Coale-McNeil model (with 4 parameters), as well as the simple version eq(8) of the proposed model. Selected results corresponding to the female populations are illustrated in Figures 1 to 3 (the corresponding figures for males are omitted). In cases where the simple models cannot adequately estimate the age-specific marriage distribution, we fit the mixture models, i.e., the Coale-McNeil mixture model as described in Liang (2000), as well as the two mixture versions of the proposed model (Mixture Model 1 and Mixture Model 2). Selected results are then illustrated in Figures 4 to 6.

Evaluation of the fits of the various simple models, according to the values of the error sum of squares (Table 5), indicates that the Standard Coale-McNeil model performs worse than all the other models, while the Coale-McNeil model has a somewhat better performance than the GLG model and the simple version of our model. The simple version of our model gives a somewhat 
higher error sum of squares than the other two. However, graphical examination of the observed and fitted age-specific first-marriage rates (here illustrated for Spain, Norway, and Ireland) suggest that our basic model eq(8) shows better performance in the left tail of the marriage curve, while the two other (GLG and Coale-McNeil) fit better the right tail of the curve. In any case, all these three models show similar behaviour, providing in general poor fits at the tails and the peak of the agespecific first marriage rates.

The poor fit of simple models, previously noted by Liang (2000) for Chinese data, seems to be actual in modern European populations too. Liang (2000) evaluated the double exponential distribution for Chinese women and found that this model failed in some cases to fit well the age-specific first marriage pattern of these populations. He also found that in some cases the peak value of the observed rates is not described well by the model. He supposed that this might be related to a possible appearance of heaping at ages of first marriage, since before 1976 Chinese people preferred to report the age of their marriage as 18 years. However, this is a problem that appears even when the models are fitted to European data, as our examples indicate. Liang (2000) made the plausible hypothesis that the observations may come from two different groups, a hypothesis that was initially developed by Chandola et al. (1999) for fertility data. Therefore, the observed data are considered to be a mixture of two distributions, since there is a group of women that marry earlier. Kaneko (2003) has also mentioned that the systematic deviations between observed and estimated rates are due to systematic errors derived from simplification or insufficiency in model specification.

Regarding our analyses, similar conclusions to those provided by Liang can be drawn about the fits of simple models in European data. For all the populations examined, simple models fail to provide close fits of the observed rates over the whole age range. In the case of Spain, Ireland, Finland, and Sweden, the models fail to closely estimate the tails and the peak value of the marriage distribution. For the UK and Netherlands, the models fit the left part of the marriage distribution quite well, but show important distortions between the observed and estimated rates of the right part of the marriage distribution. Graphical evaluation of the results indicates the existence of a bulge at young ages for the Swedish data as well as the existence of a less intense bulge at older ages. The bulge at young ages appears around age 20 , while that in the older ages appears around age 40 . We also observe that a bulge has started to appear for older people in the populations of Finland, Norway, and, to a lesser extent, Ireland.

Following the hypotheses of Liang (2000) and Chandola et al. (1999), as well as that of Peristera and Kostaki (2007) for fertility data, our hypothesis here also is that these findings imply the existence in the populations of heterogeneity related to the age that women are married. Therefore, we suppose that the observed data come from two different distributions (one for each subpopulation), and in such cases the use of mixture models is required (Chandola et al. 1999; Liang 2000; Peristera and Kostaki 2007).

Turning now to the results of fitting the mixture models, the values of the error sum of squares are presented in Table 5, as well as in Figures 4 to 6 for selected populations. The main findings are that Mixture Models 1 and 2 have by far better performance than all the other models, including the Coale-McNeil mixture model, while Mixture Model 2 is, as expected, superior to Mixture Model 1. It is obvious that mixture models provide significantly better fits that the simple models over the total age span of the empirical data. Mixture Models 1 and 2 both provide far more successful fits in the peak and the tails of the distribution in all cases. The Coale-McNeil mixture model, though it comprises one more parameter than Mixture Model 1 and equal number of parameters as Mixture Model 2 , underestimates the tails of the distribution, and it clearly provides inferior fits to both the proposed 
mixture models. The only exception which the Coale-McNeil mixture model fits better is for the UK in the year 1996. It is also remarkable that all the mixture models failed to perfectly estimate the marriage distribution for the Swedish female population in the year 2002. This is related to the very distinct shape of the marriage curve, consisting of two bulges at young ages and another one at older ages. In fact, it is an indication that this population consists of more than two subpopulations that might have distinct characteristics regarding the age at marriage.

From our analysis, it comes out that simple models cannot closely fit the marriage curves in all modern European populations. As stated in the literature, this might be an indication that the observed data come from two or more distributions, indicating great heterogeneity in the population regarding its behaviour towards marriage. It is of course a matter of great interest to identify and describe the sources of heterogeneity in nuptiality. In order to take into account this heterogeneity, different explanations in each population separately should be considered, based on a country's sociopolitical, migration, religion, and historical background. Regarding Spain, a possible explanation for the existence of heterogeneity in marriages might be the growth of immigrant populations from third-world origins that have higher and earlier patterns of marriages compared to those of the indigenous populations. Religiosity may also contribute to the existence of this bulge in the age-specific marriage distributions of other countries. In the case of Ireland, the heterogeneity may be related to the fact that Catholicism is very powerful in the Irish population, and although abortions are legal, the Catholic Church does not allow them. In Scandinavian countries, heterogeneity in the marriage pattern could also be associated with second-generation immigrants from Arabic and Middle Eastern countries. Finally, education and socioeconomic status might play important roles in the existence of the bulge at earlier ages of the marriage curve, especially for the population of the UK.

As mentioned above, a variety of factors related to the socioeconomic and cultural background of male and female populations may contribute to the appearance of heterogeneity in the marriage curve. This evidence of heterogeneity in the marriage curve, as implied by the fit of mixture models, could be further explained with the use of appropriate empirical data. In that case, it would be of interest to compare different simple and mixture models from the ones proposed here to estimate the age-specific nuptiality curves of subpopulations.

The parametric models proposed and evaluated in this work have as their objective the estimation of age-specific rates based on nuptiality data, but using an age-dependent function whose parameters are adjusted from the crude rates obtainable directly from the data. For this purpose, an alternative approach would be the use of nonparametric graduation techniques. Nonparametric graduation aims to obtain new values from the original data, in which any influence that does not come from the predictor variable is eliminated, and contrary to parametric graduation, a function that expresses the relationship between marriage rates, and age is not provided. In other words, the use of nonparametric graduation of nuptiality data would allow estimating marriage rates by carrying out a smoothing of the crude rates obtained directly from original data. The main difference with regard to parametric models is that the assumption of an age-dependent function is unnecessary, which is advantageous when the information behind the model is unknown, as one cause of error is often the choice of an inappropriate model.

Parametric and nonparametric methods can complement each other in certain cases, in the sense that the result of nonparametric graduation can more adequately describe the type of equation to be used. Moreover, nonparametric methods can be used to carry out a diagnosis of parametric models, or simply to examine data. With this perspective, it would be also of interest to fit these data using non-parametric techniques, such as kernel estimates and support vector machines. Previous work has 
shown that nonparametric estimation of demographic rates, based on kernels and support vector machines, is very efficient and very useful for tracing irregularities in the data, and provides smooth estimates (Peristera and Kostaki 2005; Kostaki et al. 2009).

\section{Conclusions}

Alternative models have been proposed in the literature for estimating the marriage distribution. Recent evidence indicates that these models are often inadequate for estimating the pattern of first marriages in modern populations. A probable hypothesis for explaining this fact is that these populations are heterogeneous regarding their behaviour towards marriage, and their nuptiality curve deviates from the standard one. In such populations a new marriage pattern has started to arise, which consists of a second bulge at earlier ages. So far, this was described for Chinese women by Liang (2000), and a mixture model was proposed for dealing with this problem.

In this work, three versions of a parametric model are proposed and evaluated. Initially, a basic four-parameter formula for fitting the age-specific marriage distribution is developed. Then, two mixture versions of the basic model are presented, suitable for datasets exhibiting heterogeneity, where simple models fail to adequately describe the distorted shape of the marriage distribution. In order to evaluate the adequacy of these three formulae, we fit them to empirical datasets of several populations. Furthermore, we compare these models to previously existing ones, such as the standard Coale-McNeil model, the four-parameter Coale-McNeil model, the Generalized Log Gamma model, and the mixture seven-parameter Coale-McNeil model, fitting them to the same datasets.

A general remark from our analyses is that simple models cannot provide close fits in the tails of the curve, and they also fail to capture the peak value of the marriage distribution.

Regarding Mixture Model 1 and Mixture Model 2, we conclude that both provide successful fits of the age-specific marriage distributions, while the Coale-McNeil mixture model gives poorer fits in all cases. It is also remarkable that although Mixture Model 1 requires one less parameter to be estimated than the Coale-McNeil mixture model, it provides by far better results than the latter. Furthermore, Mixture Model 2 comprises the same number of parameters as the Coale-McNeil mixture model, but the former fits much better and also it is much simpler and easier to interpret.

The parameters of the Mixture Model 1 and Mixture Model 2 have an explicit interpretation while they can be utilized for understanding the shape of the marriage pattern, as well as for facilitating comparisons through time and place, cohorts, and population subgroups.

An interesting finding of our analysis is that for Swedish male and female populations, three bulges have appeared, indicating a very heterogeneous behaviour in relation to marriage. Heterogeneity also characterizes the marriage distributions of other female populations, such as Finland and Norway, indicating that in these populations there is a group of women that marries at a relatively old age, i.e., around their 40s - a fact that to some extent may be related to the modernization of society regarding women and their role in the society, as well as their changing behaviour in regards of their professional career. Another possible explanation that needs further research is that these populations have been heterogeneous due to the growth of second-generation immigrant populations from third-world origins, with higher and earlier patterns of first marriages than the indigenous populations. Other factors may be associated with this heterogeneity, such as educational level and economic status, as well as regional profiles.

As a concluding remark, we consider that the parametric model proposed in this paper proves quite sufficient for describe first marriage distributions of modern populations. Depending on the 
Peristera and Kostaki: A parametric model for estimating nuptiality patterns in modern populations

population examined and taking into account its specific characteristics, the basic model, or one of the mixture versions 1 and 2, can be selected for describing the marriage distribution of the population. Our calculations showed that the two mixture versions provide much better results than all the other models, for all cases examined. Therefore, they can be considered as useful tools for capturing the first marriage distribution of modern populations.

A further advantage of this new parametric model is that it can be fitted to both fertility and nuptiality age-specific rates of a population; thus, using the parameter estimates of the two fits allows comparisons between fertility and nuptiality behaviours in the population considered.

\section{References}

Bloom, D. 1980. Age Patterns of Women at First Birth. Essays in Labor Economics and Demography. PhD diss., Princeton University. Ann Arbor, MI: University Microfilms.

- 1982. What's happening to the age at first birth in the United States? A study of recent cohorts. Demography 19(3):351-70.

Bloom, D., and H.N. Bennett. 1990. Modeling American marriage patterns. Journal of the American Statistical Association 85(412):1009-17.

Bongaarts, J., and G. Feeney. 1998. On the quantum and tempo of fertility. Population and Development Review 24:271-92.

Casterline, J., and J. Trussell. 1980. Age at First Birth. Comparative Studies 15. London: World Fertility Survey.

Chandola, T., D.A. Coleman, and R.W. Hiorns. 1999. Recent European fertility patterns: Fitting curves to 'distored' distributions. Population Studies 53:317-29.

Coale, A. 1971. Age patterns of marriage. Population Studies 25(2):193-214.

Coale, A.J., and D.R. McNeil. 1972. The distribution by age of the frequency of first marriage in a female cohort. Journal of the American Statistical Association 67(340):743-49.

Feeney, G.M. 1972. Marriage Rates and Population Growth: The Two-sex Problem in Demography. $\mathrm{PhD}$ diss., University of California, Berkeley.

Goldstein, J.R., and C.T. Kenney. 2001. Marriage delayed or marriage forgone? New cohort forecasts of first marriage for U. S. women. American Sociological Review 66(4):506-19.

Hernes, G. 1972. The process of entry into first marriage. American Sociological Review 37:173-82.

Hobcraft, J., and J. Trussell. 1980. A note on the Analysis of Maternity Histories by Birth Order. WFS/TECH 1305. London: World Fertility Survey.

Hoem, J.M. 1976. The statistical theory of demographic rates: A review of current developments with discussion. Scandinavian Journal of Statistics 3:169-85.

Kaneko, R. 1991. Demographic analysis of the first marriage process. The Journal of Population Problems 47(3):3-27.

. 2003. Elaboration of the Coale-McNeil nuptiality model as the generalised log gamma distribution: A new identity and empirical enhancements. Demographic Research 9(10):224-62. 
2005. Cohort Process to the Lowest Fertility in Japan: Application of an Empirically Adjusted Coale-McNeil Model to the Estimation and Projection of Life Time Measures of First Measures of First Marriage and Birth. Paper presented at Joint Eurostat-UNECE Work Session on Demographic Projections, Vienna, 21-23 September.

Keeley, M.C. 1979. An analysis of the age pattern of first marriages. International Economic Review 202:527-44.

Kohler, H-P., and D. Philipov. 2001. Variance effects in the Bongaarts-Feeney formula. Demography 38(1):1-16.

Kohler, H-P., and J.A. Ortega. 2002. Tempo-adjusted period parity progression measures, fertility, postponement and completed cohort fertility. Demographic Research 66:91-144. http://www. demographic-research.org/Volumes/Vol6/6-6.pdf

Kojima, H. 1985. About the Coale-McNeil Nuptiality Model. Jinkou Mondai Kenkyu 175:36-47.

Kostaki, A., J.M. Moguerza, A. Olivares, and S. Psarakis. 2009. Graduating the age-specific fertility pattern using Support Vector Machines. Demographic Research 20(25):599-622.

Liang, Z. 2000. The Coale-McNeil Model: Theory, Generalisation and Application. Thela Thesis, Amsterdam, The Netherlands.

Peristera, P., and A. Kostaki. 2005. An evaluation of the performance of kernel estimators for graduating mortality data. Journal of Population Research 22(2):185-97.

—. 2006. Modeling fertility in modern populations. Demographic Research 166:141-96.

Prentice, R.L. 1974. A log gamma model and its maximum likehood estimation. Biometrica 613:539-44.

Rodriguez, G., and J. Trussell. 1980. Maximum Likelihood Estimation of the Parameter of Coale's Model Nuptiality Schedule from Survey Data. Technical Bulletins 7. London: World Fertility Survey.

Ryder, N.B. 1964. The process of demographic translation. Demography 11:74-82.

1980. Components of temporal variations in American fertility, in Demographic Patterns in Developed Societies, edited by R.W. Hiorns. London: Taylor and Francis, p: 15-54.

Takahashi, S. 1978. Application of the Nuptiality Model Schedule to Japan. Kokumin, Keirai Zasshi 138(6):80-95.

Trussell, J., and D. Bloom. 1981. Estimating the Covariates of Age at Marriage and First Birth. Duplicated. Office of Population Research, Princeton University.

Trussell, J., J. Menken, and A. Coale. 1981. A general model for analyzing the effect of nuptiality and fertility, in Nuptiality and Fertility: Proceedings of a Conference, edited by L. Ruzicka. Liege (France): Ordina Editions, p. 7-26. 


\section{APPENDIX}

Table 1. Parameter estimates, Coale-McNeil model and GLG model, females \& males.

\begin{tabular}{|c|c|c|c|c|c|c|c|c|}
\hline \multirow{2}{*}{ Females } & \multicolumn{4}{|c|}{ Coale-McNeil model } & \multicolumn{4}{|c|}{ GLG model } \\
\hline & $C$ & $b$ & $\lambda$ & $\mu$ & $C$ & $b$ & $\lambda$ & $\mu$ \\
\hline \multicolumn{9}{|l|}{ Spain } \\
\hline 1995 & 0.93 & 0.08 & 0.57 & 57.38 & 0.02 & 3.67 & -0.51 & 25.69 \\
\hline 2002 & 0.95 & 0.08 & 0.54 & 58.77 & 0.01 & 3.67 & -0.48 & 26.01 \\
\hline \multicolumn{9}{|c|}{ Netherlands } \\
\hline 1998 & 0.56 & 0.10 & 0.56 & 42.41 & 0.07 & 4.12 & -0.54 & 26.21 \\
\hline 2001 & 0.55 & 0.10 & 0.59 & 42.64 & 0.22 & 4.17 & -0.60 & 26.24 \\
\hline \multicolumn{9}{|l|}{ Norway } \\
\hline 1996 & 0.38 & 0.15 & 0.57 & 32.12 & 0.44 & 4.13 & -0.66 & 26.09 \\
\hline 2002 & 0.36 & 0.14 & 0.59 & 32.52 & 0.61 & 4.39 & -0.71 & 26.12 \\
\hline \multicolumn{9}{|l|}{ Sweden } \\
\hline 1997 & 0.28 & 0.17 & 0.41 & 30.34 & 0.47 & 4.58 & -0.75 & 27.21 \\
\hline 2002 & 0.32 & 0.15 & 0.39 & 32.81 & 0.39 & 4.57 & -0.71 & 27.44 \\
\hline \multicolumn{9}{|l|}{ Finland } \\
\hline 1998 & 0.34 & 0.16 & 0.56 & 30.35 & 0.61 & 4.26 & -0.73 & 25.56 \\
\hline 2002 & 0.29 & 0.18 & 0.57 & 28.53 & 0.69 & 4.32 & -0.77 & 25.63 \\
\hline \multicolumn{9}{|l|}{ Ireland } \\
\hline 1993 & 0.45 & 0.22 & 0.62 & 28.98 & 0.75 & 3.16 & -0.76 & 25.73 \\
\hline 1998 & 0.41 & 0.23 & 0.61 & 28.43 & 0.71 & 3.21 & -0.75 & 26.08 \\
\hline \multicolumn{9}{|l|}{ UK } \\
\hline 1996 & 0.32 & 0.19 & 0.52 & 27.51 & 0.66 & 4.09 & -0.80 & 24.67 \\
\hline 1999 & 0.33 & 0.17 & 0.52 & 28.61 & 0.61 & 4.19 & -0.75 & 24.97 \\
\hline \multicolumn{8}{|l|}{ Males } & $\mu$ \\
\hline \multicolumn{9}{|l|}{ Spain } \\
\hline 1995 & 0.59 & 0.14 & 0.64 & 36.39 & 0.26 & 3.44 & -0.60 & 26.09 \\
\hline 2002 & 0.59 & 0.13 & 0.63 & 37.82 & 0.23 & 3.52 & -0.60 & 26.38 \\
\hline \multicolumn{9}{|c|}{ Netherlands } \\
\hline 1998 & 0.51 & 0.41 & 0.79 & 21.46 & 0.96 & 2.18 & -0.89 & 20.91 \\
\hline 2001 & 0.47 & 0.48 & 0.75 & 20.81 & 0.74 & 2.12 & -1.009 & 20.84 \\
\hline \multicolumn{9}{|l|}{ Norway } \\
\hline 1996 & 0.28 & 0.18 & 0.54 & 30.76 & 0.69 & 4.47 & -0.81 & 28.39 \\
\hline 2002 & 0.25 & 0.19 & 0.49 & 29.995 & 0.63 & 4.57 & -0.86 & 28.65 \\
\hline \multicolumn{9}{|l|}{ Sweden } \\
\hline 1997 & 0.21 & 0.22 & 0.39 & 28.88 & 0.40 & 4.67 & -0.99 & 29.14 \\
\hline 2002 & 0.21 & 0.22 & 0.38 & 28.94 & 0.43 & 4.73 & -0.94 & 29.36 \\
\hline \multicolumn{9}{|l|}{ Finland } \\
\hline 1998 & 0.28 & 0.20 & 0.51 & 27.48 & 0.65 & 4.17 & -0.85 & 25.84 \\
\hline 2002 & 0.26 & 0.21 & 0.53 & 26.95 & 0.64 & 4.29 & -0.90 & 25.99 \\
\hline \multicolumn{9}{|l|}{ Ireland } \\
\hline 1993 & 0.31 & 0.16 & 0.49 & 31.99 & 0.58 & 4.4 & -0.76 & 27.98 \\
\hline 1998 & 0.31 & 0.17 & 0.66 & 31.69 & 0.78 & 4.29 & -0.76 & 28.36 \\
\hline \multicolumn{9}{|l|}{ UK } \\
\hline 1996 & 0.23 & 0.21 & 0.54 & 27.68 & 0.63 & 4.58 & -0.93 & 27.32 \\
\hline 1999 & 0.27 & 0.18 & 0.52 & 29.48 & 0.66 & 4.47 & -0.82 & 27.22 \\
\hline
\end{tabular}


Table 2. Parameter estimates, Standard Coale-McNeil model and Model, females \& males.

\begin{tabular}{|c|c|c|c|c|c|c|c|}
\hline \multirow{2}{*}{ Females } & \multicolumn{3}{|c|}{ Standard Coale-McNeil } & \multicolumn{4}{|c|}{ Model } \\
\hline & $a_{0}$ & $k$ & $C$ & $c_{1}$ & $\mu$ & $\sigma_{11}$ & $\sigma_{12}$ \\
\hline \multicolumn{8}{|l|}{ Spain } \\
\hline 1995 & 19.19 & 0.59 & 0.75 & 0.06 & 25.83 & 4.88 & 5.62 \\
\hline 2002 & 19.51 & 0.57 & 0.75 & 0.06 & 26.09 & 4.83 & 5.66 \\
\hline \multicolumn{8}{|c|}{ Netherlands } \\
\hline 1998 & 18.74 & 0.59 & 0.86 & 0.05 & 26.11 & 5.09 & 6.73 \\
\hline 2001 & 18.75 & 0.61 & 0.87 & 0.05 & 26.20 & 5.17 & 6.83 \\
\hline \multicolumn{8}{|l|}{ Norway } \\
\hline 1996 & 18.73 & 0.59 & 0.87 & 0.05 & 25.86 & 4.83 & 0.05 \\
\hline 2002 & 18.28 & 0.62 & 0.93 & 0.05 & 25.83 & 5.03 & 0.05 \\
\hline \multicolumn{8}{|l|}{ Sweden } \\
\hline 1997 & 19.15 & 0.42 & 0.96 & 0.03 & 27.01 & 5.34 & 8.04 \\
\hline 2002 & 19.48 & 0.41 & 0.95 & 0.03 & 27.11 & 5.19 & 8.12 \\
\hline \multicolumn{8}{|l|}{ Finland } \\
\hline 1998 & 17.96 & 0.58 & 0.90 & 0.05 & 25.23 & 4.80 & 7.64 \\
\hline 2002 & 17.96 & 0.58 & 0.92 & 0.05 & 25.21 & 4.72 & 8.02 \\
\hline \multicolumn{8}{|l|}{ Ireland } \\
\hline 1993 & 20.18 & 0.64 & 0.66 & 0.07 & 25.46 & 3.52 & 5.77 \\
\hline 1998 & 20.43 & 0.62 & 0.67 & 0.07 & 25.72 & 3.49 & 5.96 \\
\hline \multicolumn{8}{|l|}{ UK } \\
\hline 1996 & 17.41 & 0.54 & 0.87 & 0.05 & 24.19 & 4.38 & 7.73 \\
\hline 1999 & 17.52 & 0.53 & 0.88 & 0.05 & 24.52 & 4.57 & 7.75 \\
\hline \multicolumn{8}{|l|}{ Males } \\
\hline & $a_{0}$ & $k$ & $C$ & $c_{1}$ & $\mu$ & $\sigma_{11}$ & $\sigma_{12}$ \\
\hline \multicolumn{8}{|l|}{ Spain } \\
\hline 1995 & 19.94 & 0.67 & 0.72 & 0.07 & 26.01 & 4.22 & 5.71 \\
\hline 2002 & 20.11 & 0.65 & 0.73 & 0.07 & 26.36 & 4.39 & 5.74 \\
\hline \multicolumn{8}{|c|}{ Netherlands } \\
\hline 1998 & 17.06 & 0.81 & 0.47 & 0.13 & 20.66 & 2.29 & 4.22 \\
\hline 2001 & 17.13 & 0.77 & 0.46 & 0.13 & 20.54 & 2.13 & 4.32 \\
\hline \multicolumn{8}{|l|}{ Norway } \\
\hline 1996 & 20.55 & 0.56 & 0.94 & 0.05 & 27.78 & 4.6732 & 8.62 \\
\hline 2002 & 20.63 & 0.51 & 0.97 & 0.04 & 27.95 & 4.64 & 9.05 \\
\hline \multicolumn{8}{|l|}{ Sweden } \\
\hline 1997 & 20.99 & 0.39 & 1.003 & 0.03 & 28.37 & 4.55 & 9.69 \\
\hline 2002 & 21.15 & 0.39 & 1.004 & 0.03 & 28.51 & 4.53 & 9.74 \\
\hline \multicolumn{8}{|l|}{ Finland } \\
\hline 1998 & 18.49 & 0.53 & 0.89 & 0.05 & 25.29 & 4.36 & 8.07 \\
\hline 2002 & 18.45 & 0.54 & 0.92 & 0.05 & 25.32 & 4.32 & 8.62 \\
\hline \multicolumn{8}{|l|}{ Ireland } \\
\hline 1993 & 20.16 & 0.52 & 0.93 & 0.04 & 27.55 & 4.89 & 8.17 \\
\hline 1998 & 20.77 & 0.68 & 0.90 & 0.06 & 27.96 & 4.77 & 7.89 \\
\hline \multicolumn{8}{|l|}{ UK } \\
\hline 1996 & 19.29 & 0.56 & 0.99 & 0.04 & 26.53 & 4.48 & 9.34 \\
\hline 1999 & 19.34 & 0.53 & 0.95 & 0.04 & 26.62 & 4.68 & 8.61 \\
\hline
\end{tabular}


Table 3. Parameter estimates, Coale-McNeil mixture model, females \& males.

\begin{tabular}{|c|c|c|c|c|c|c|c|}
\hline \multirow{2}{*}{ Females } & \multicolumn{7}{|c|}{ Coale-McNeil Mixture model } \\
\hline & $a_{1}$ & $\lambda_{1}$ & $m$ & $\mu_{1}$ & $\lambda_{2}$ & $a_{2}$ & $\mu_{2}$ \\
\hline \multicolumn{8}{|l|}{ Spain } \\
\hline 1995 & 0.05 & 0.028 & 0.49 & 8.32 & 0.09 & 0.91 & 49.57 \\
\hline 2002 & 0.05 & 0.026 & 0.51 & 12.88 & 0.11 & 0.81 & 44.44 \\
\hline \multicolumn{8}{|c|}{ Netherlands } \\
\hline 1998 & 0.06 & 0.024 & 0.46 & 2.37 & 0.13 & 0.49 & 37.18 \\
\hline 2001 & 0.01 & 0.037 & 0.43 & 12.86 & 0.11 & 0.56 & 41.57 \\
\hline \multicolumn{8}{|l|}{ Sweden } \\
\hline 1997 & 0.03 & 27.27 & 4.79 & 0.01 & 30.79 & 10.40 & 0.026 \\
\hline 2002 & 0.02 & 27.409 & 4.55 & 0.01 & 30.58 & 10.24 & 0.024 \\
\hline \multicolumn{8}{|l|}{ Finland } \\
\hline 1998 & 0.004 & 0.069252 & 0.48 & 14.46 & 0.15 & 0.39 & 32.21 \\
\hline 2002 & 0.006 & 11.515 & 0.51 & 17.09 & 0.17 & 0.37 & 29.89 \\
\hline \multicolumn{8}{|l|}{ Ireland } \\
\hline 1993 & 0.029 & 0.017351 & 0.42 & 7.31 & 0.22 & 0.49 & 29.37 \\
\hline 1998 & 0.027 & 0.015559 & 0.43 & 9.763 & 0.23 & 0.47 & 29.41 \\
\hline \multicolumn{8}{|l|}{ UK } \\
\hline 1996 & 0.041 & 24.503 & 4.78 & 0.01 & 29.92 & 7.37 & 0.04 \\
\hline 1999 & 0.041 & 24.835 & 4.97 & 0.01 & 30.48 & 7.62 & 0.04 \\
\hline \multicolumn{8}{|l|}{ Males } \\
\hline & $a_{1}$ & $\lambda_{1}$ & $m$ & $\mu_{1}$ & $\lambda_{2}$ & $a_{2}$ & $\mu_{2}$ \\
\hline \multicolumn{8}{|l|}{ Spain } \\
\hline 2002 & 0.13 & 0.56 & 16.56 & 20.91 & 0.59 & 0.13 & 20.83 \\
\hline \multicolumn{8}{|c|}{ Netherlands } \\
\hline 2002 & $3.55 \mathrm{E}-1<$ & 40.042016 & 0.48 & 2.46 & 0.31 & 0.17 & 26.14 \\
\hline \multicolumn{8}{|l|}{ Sweden } \\
\hline 1997 & 0.08 & 0.02 & 0.61 & 19.51 & 0.28 & 0.17 & 27.16 \\
\hline 2001 & 0.17 & 0.014 & 0.62 & 17.98 & 0.22 & 0.21 & 29.21 \\
\hline \multicolumn{8}{|l|}{ Finland } \\
\hline 2002 & 0.007 & 0.007 & 0.50 & 51.56 & 0.19 & 0.29 & 27.97 \\
\hline \multicolumn{8}{|l|}{ Ireland } \\
\hline 1998 & 0.39 & 0.15 & 0.61 & 34.828 & 0.014 & 0.02 & 76.50 \\
\hline
\end{tabular}


Table 4. Parameter estimates, Mixture Model 1 and Mixture Model 2, females \& males.

\begin{tabular}{|c|c|c|c|c|c|c|c|c|c|c|c|c|c|}
\hline \multirow{2}{*}{ Females } & \multicolumn{6}{|c|}{ Mixture Model 1} & \multicolumn{7}{|c|}{ Mixture Model 2} \\
\hline & $c_{1}$ & $m_{1}$ & $\sigma_{11}$ & $c_{2}$ & $m_{2}$ & $\sigma_{2}$ & $c_{1}$ & $m_{1}$ & $\sigma_{11}$ & $\sigma_{12}$ & $c_{2}$ & $m_{2}$ & $\sigma_{2}$ \\
\hline \multicolumn{14}{|l|}{ Spain } \\
\hline 1995 & 0.05 & 25.91 & 4.05 & 0.02 & 27.03 & 8.59 & 0.04 & 25.95 & 4.13 & 3.93 & 0.02 & 27.12 & 8.43 \\
\hline 2002 & 0.04 & 26.18 & 3.99 & 0.02 & 27.38 & 8.69 & 0.04 & 26.19 & 4.02 & 3.98 & 0.02 & 27.40 & 8.69 \\
\hline \multicolumn{14}{|c|}{ Netherlands } \\
\hline 1998 & 0.04 & 25.38 & 5.88 & 0.01 & 32.13 & 8.45 & 0.05 & 25.21 & 5.59 & 6.89 & 0.01 & 36.19 & 9.39 \\
\hline 2001 & 0.04 & 27.66 & 4.34 & 0.02 & 31.11 & 10.52 & 0.04 & 28.18 & 5.15 & 3.42 & 0.02 & 31.43 & 9.58 \\
\hline \multicolumn{14}{|l|}{ Sweden } \\
\hline 1997 & 0.02 & 27.27 & 4.79 & 0.01 & 30.79 & 10.40 & 0.03 & 27.51 & 5.38 & 4.29 & 0.01 & 31.36 & 9.60 \\
\hline 2002 & 0.02 & 27.41 & 4.55 & 0.01 & 30.58 & 10.24 & 0.02 & 27.32 & 4.37 & 4.73 & 0.01 & 30.46 & 10.45 \\
\hline \multicolumn{14}{|l|}{ Finland } \\
\hline 1998 & 0.05 & 25.57 & 5.14 & 0.01 & 31.95 & 8.48 & 0.05 & 25.49 & 5.04 & 5.49 & 0.01 & 32.62 & 8.78 \\
\hline 2002 & 0.04 & 25.46 & 4.89 & 0.01 & 31.06 & 8.52 & 0.04 & 25.48 & 4.91 & 4.83 & 0.01 & 31.03 & 8.44 \\
\hline \multicolumn{14}{|l|}{ Ireland } \\
\hline 1993 & 0.06 & 25.76 & 3.69 & 0.02 & 29.50 & 7.04 & 0.06 & 25.63 & 3.43 & 4.08 & 0.02 & 29.31 & 7.88 \\
\hline 1998 & 0.06 & 26.02 & 3.73 & 0.02 & 29.76 & 6.73 & 0.06 & 25.85 & 3.37 & 4.42 & 0.01 & 29.71 & 8.18 \\
\hline \multicolumn{14}{|l|}{ Males } \\
\hline & $c_{1}$ & $m_{1}$ & $\sigma_{11}$ & $c_{2}$ & $m_{2}$ & $\sigma_{2}$ & $c_{1}$ & $m_{1}$ & $\sigma_{11}$ & $\sigma_{12}$ & $c_{2}$ & $m_{2}$ & $\sigma_{2}$ \\
\hline \multicolumn{14}{|l|}{ Spain } \\
\hline 2002 & 0.06 & 26.61 & 4.48 & 4.03 & 0.01 & 30.39 & 0.06 & 26.52 & 4.30 & 0.01 & 0.06 & 30.27 & 8.74 \\
\hline \multicolumn{14}{|l|}{ Norway } \\
\hline 2002 & 0.03 & 28.26 & 4.99 & 0.01 & 33.99 & 8.23 & 0.03 & 28.14 & 4.77 & 5.55 & 0.01 & 34.19 & 8.73 \\
\hline \multicolumn{14}{|l|}{ Sweden } \\
\hline 1997 & 0.02 & 28.78 & 4.69 & 0.01 & 34 & 9.19 & 0.02 & 28.53 & 4.21 & 5.45 & 0.01 & 33.9 & 10.03 \\
\hline 2001 & 0.02 & 28.94 & 4.59 & 0.01 & 34.03 & 9.34 & 0.02 & 28.71 & 4.17 & 5.26 & 0.01 & 33.97 & 10.04 \\
\hline \multicolumn{14}{|l|}{ Finland } \\
\hline 2002 & 0.8 & 29.63 & 5.84 & 0.78 & 29.76 & 5.70 & 0.04 & 25.47 & 4.29 & 5.98 & 0.01 & 31.60 & 9.52 \\
\hline \multicolumn{14}{|l|}{ Ireland } \\
\hline 1998 & 0.05 & 28.18 & 4.78 & 0.02 & 32.73 & 8.62 & 0.05 & 28.34 & 5.11 & 4.28 & 0.02 & 32.92 & 7.95 \\
\hline
\end{tabular}


Peristera and Kostaki: A parametric model for estimating nuptiality patterns in modern populations

Table 5. Error sum of squares, simple \& mixture models, females.

\begin{tabular}{|c|c|c|c|c|c|c|c|}
\hline $\mathrm{SSE}^{*} 108$ & Model & $\begin{array}{c}\text { Standard } \\
\text { Coale- } \\
\text { McNeil } \\
\text { model }\end{array}$ & $\begin{array}{c}\text { GLG } \\
\text { model }\end{array}$ & $\begin{array}{l}\text { Coale- } \\
\text { McNeil } \\
\text { model }\end{array}$ & $\begin{array}{c}\text { Coale- } \\
\text { McNeil } \\
\text { mixture } \\
\text { model }\end{array}$ & $\begin{array}{l}\text { Mixture } \\
\text { Model } 1\end{array}$ & $\begin{array}{l}\text { Mixture } \\
\text { Model } 2\end{array}$ \\
\hline \multicolumn{8}{|l|}{ Females } \\
\hline \multicolumn{8}{|l|}{ Spain } \\
\hline 1995 & 14748 & 62308 & 17358 & 14058 & 6622.7 & 2262.6 & 2223.8 \\
\hline 2002 & 14376 & 46959 & 14321 & 12446 & 6250.4 & 917.6 & 914.5 \\
\hline \multicolumn{8}{|c|}{ Netherlands } \\
\hline 1996 & 4684.5 & 19516 & 2661.2 & 2563.3 & 1761.4 & 2960.3 & 1301.5 \\
\hline 2002 & 10896 & 40108 & 8704.7 & 8171.4 & 6052 & 2584 & 2201.1 \\
\hline \multicolumn{8}{|l|}{ Norway } \\
\hline 1996 & 11073 & 29525 & 8000.5 & 7828 & & & \\
\hline $2002 *$ & 7827.9 & 20803 & 5770 & 5290.5 & & & \\
\hline \multicolumn{8}{|l|}{ Sweden } \\
\hline 1997 & 11301 & 16568 & 8872.9 & 9152.2 & 8481.6 & 2688.9 & 2428.7 \\
\hline 2002 & 20068 & 32185 & 18168 & 17859 & 26983 & 3291.1 & 2891 \\
\hline \multicolumn{8}{|l|}{ Finland } \\
\hline 1993 & 14701 & 29465 & 8252.2 & 8413 & 2250.5 & 4333.8 & 4290 \\
\hline 1998 & 13410 & & 8527 & 8435.5 & 6049.4 & 3841.7 & 3704.7 \\
\hline \multicolumn{8}{|l|}{ Ireland } \\
\hline 1993 & 20961 & 31352 & 12977 & 12975 & 7388.7 & 2848.1 & 2049 \\
\hline 1998 & 18144 & 62918 & 19153 & 17110 & 8562.6 & 1765.5 & 1682.1 \\
\hline \multicolumn{8}{|l|}{ UK } \\
\hline $1996^{*}$ & 6419 & 12060 & 2271.3 & 2226.2 & & & \\
\hline $1999 *$ & 16550 & 214910 & 10280 & 10278 & & & \\
\hline \multicolumn{8}{|l|}{ Males } \\
\hline \multicolumn{8}{|l|}{ Spain } \\
\hline $1990 *$ & 16643 & 52827 & 13188 & 1219.8 & & & \\
\hline 2002 & 13465 & 22002 & 9331.2 & 9261.4 & 2928.7 & 1014.1 & 723.7 \\
\hline \multicolumn{8}{|c|}{ Netherlands } \\
\hline $1975^{*}$ & 38419 & 2350 & 15534 & 15534 & & & \\
\hline $2003 *$ & 9614.5 & 19898 & 6129.6 & 5923.6 & & & \\
\hline \multicolumn{8}{|l|}{ Norway } \\
\hline $1996^{*}$ & 9719.5 & 13648 & 6041.2 & 6040.6 & & & \\
\hline 2002 & 6104.8 & 10697 & 4133.7 & 4138.4 & 3619.4 & 1251.6 & 1097.2 \\
\hline \multicolumn{8}{|l|}{ Sweden } \\
\hline 1997 & 6372.7 & 4826.5 & 3903.7 & 3822.2 & 4302.1 & 1719.1 & 1442.5 \\
\hline 2001 & 8627.7 & 7135.3 & 5410.5 & 5381.8 & 4366.5 & 1083.3 & 1007.2 \\
\hline \multicolumn{8}{|l|}{ Finland } \\
\hline $1995^{*}$ & 9411.5 & 8290 & 3376.9 & $4349 / 7$ & & & \\
\hline 2002 & 15974 & 12020 & 7792.9 & 7790.9 & 4491.9 & 1779.4 & 1577.7 \\
\hline \multicolumn{8}{|l|}{ Ireland } \\
\hline $1996 *$ & 8034.1 & 13788 & 4467.5 & 4422.6 & & & \\
\hline 1998 & 14783 & 34290 & 12541 & 11680 & 19553 & 1156.1 & 985.1 \\
\hline \multicolumn{8}{|l|}{ UK } \\
\hline $1999 *$ & 7880.7 & 21491 & 3125.8 & 3087.7 & & & \\
\hline $2000 *$ & 6257.4 & 20437 & 2468.5 & 2460.2 & & & \\
\hline
\end{tabular}

* No need for Mixture Model. 


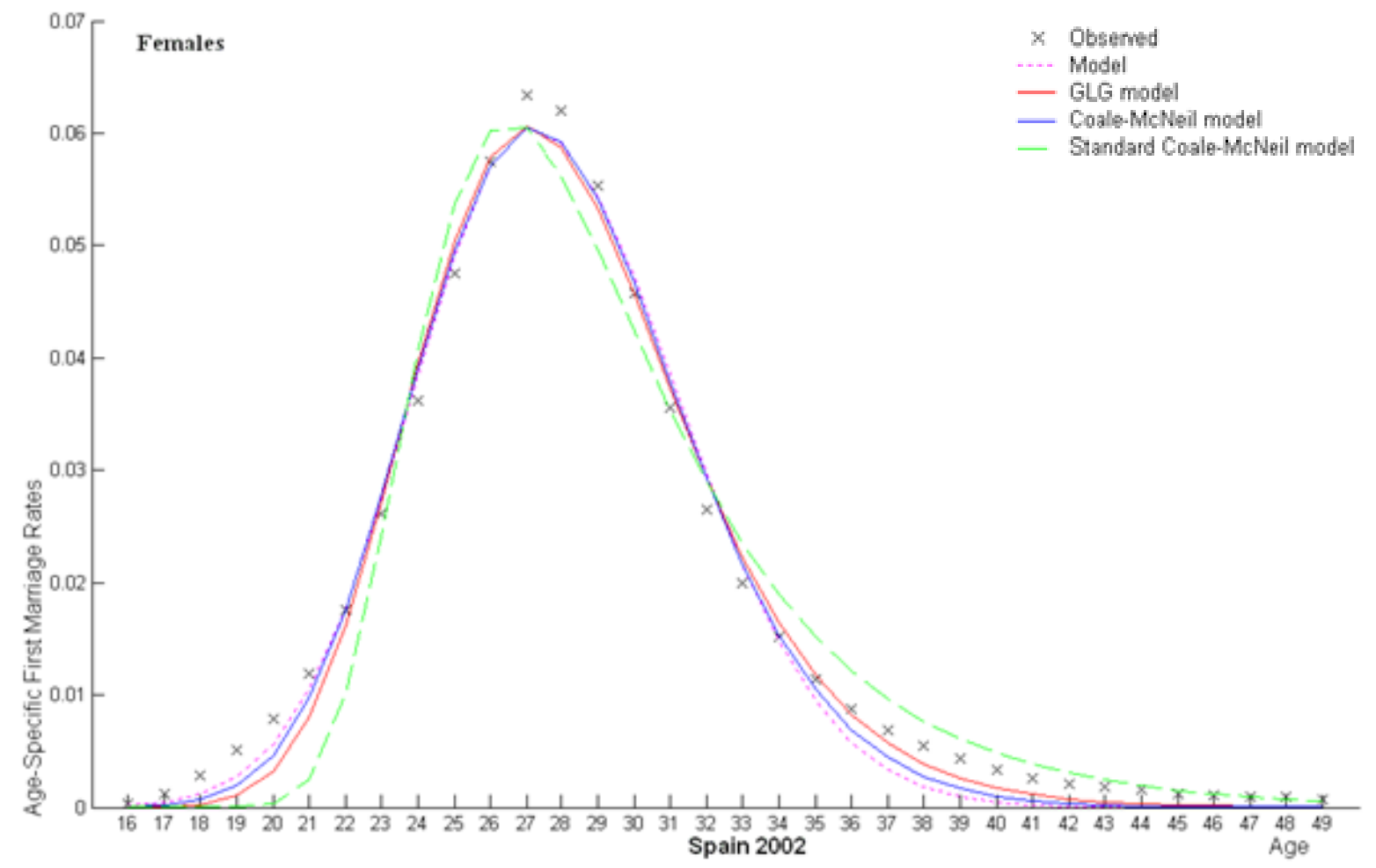

Figure 1. Observed and estimated age-specific first marriage rates of females for Spain 2002.

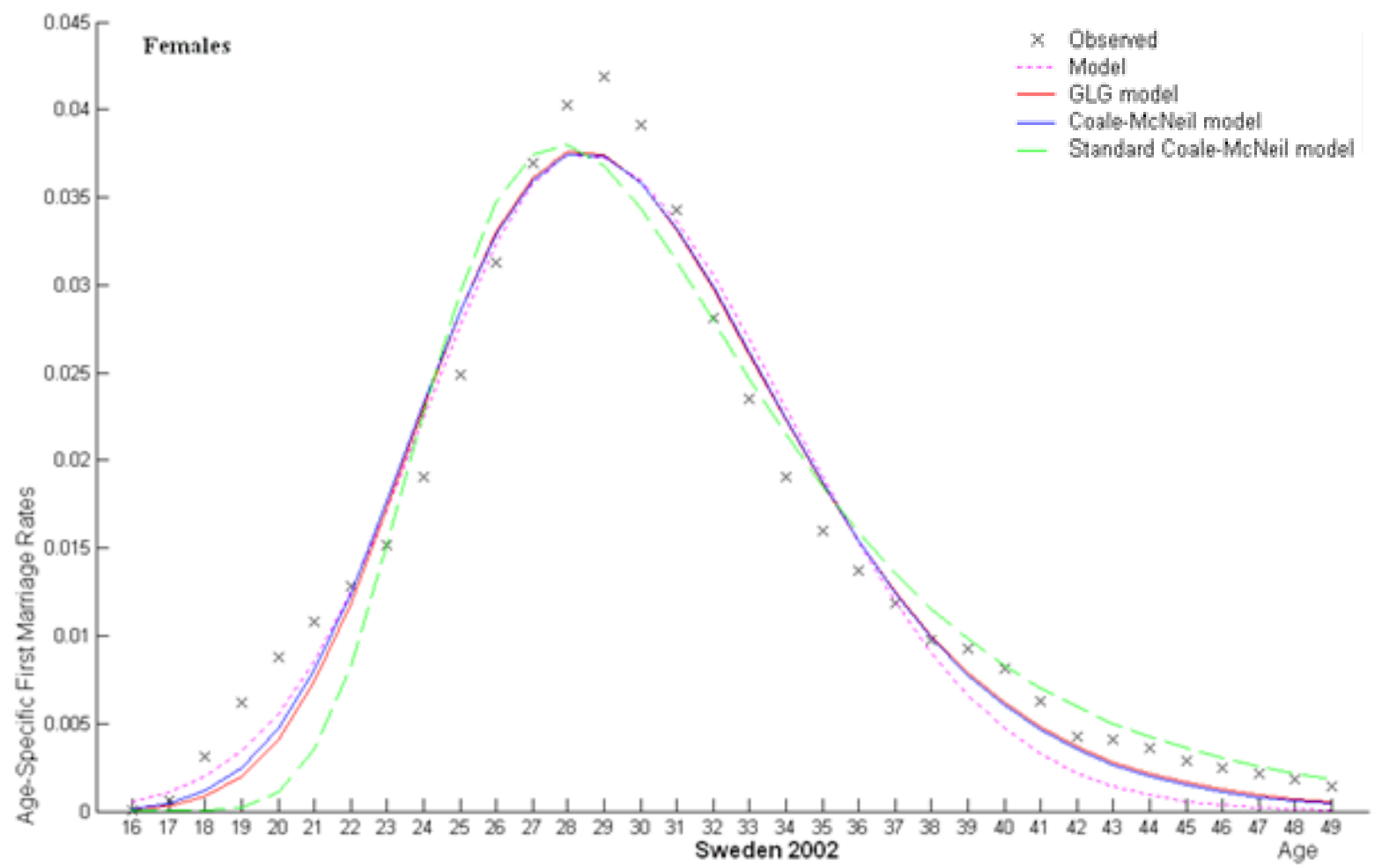

Figure 2. Observed and estimated age-specific first marriage rates of females for Sweden 2002. 
Peristera and Kostaki: A parametric model for estimating nuptiality patterns in modern populations

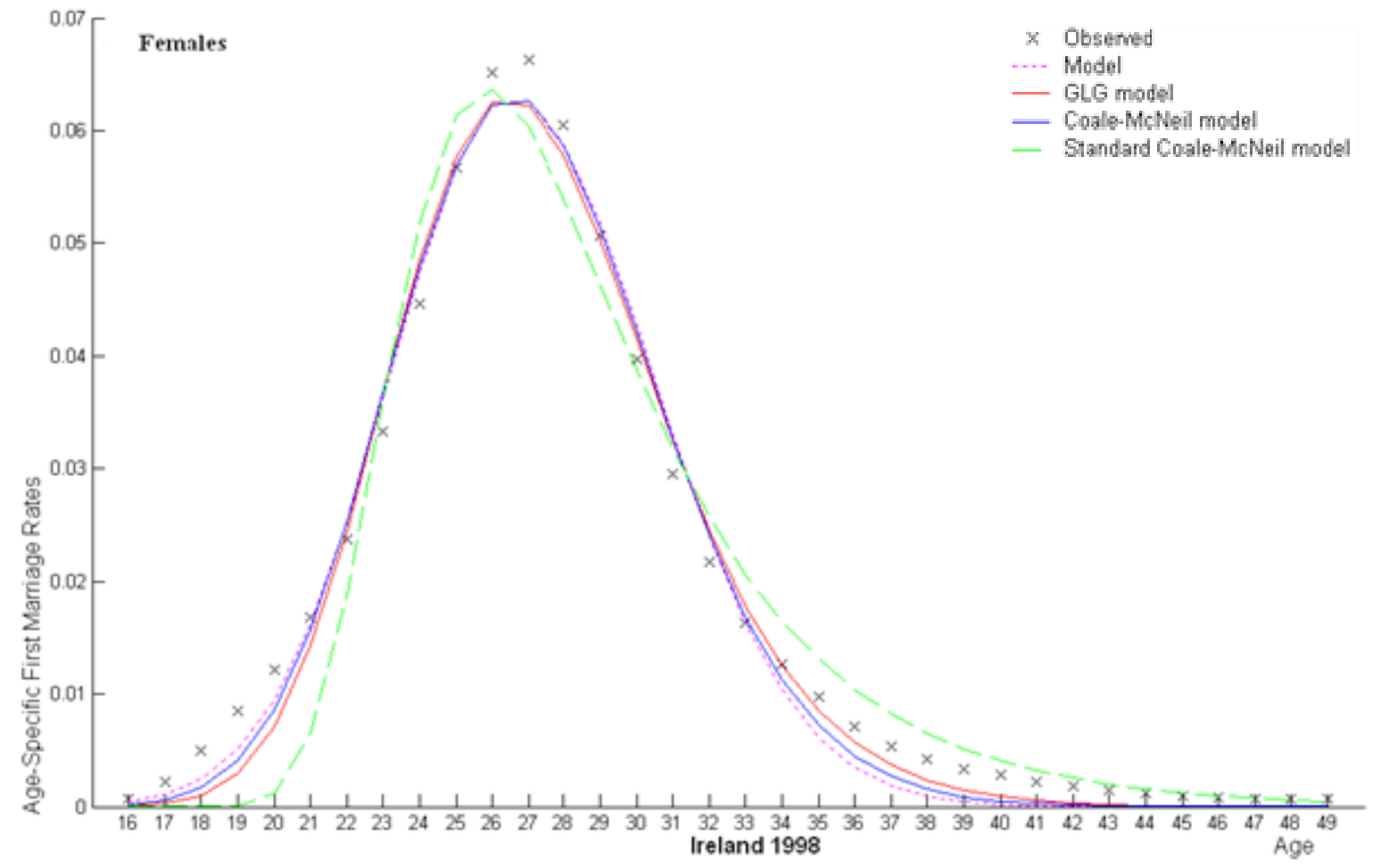

Figure 3. Observed and estimated age-specific first marriage rates of females for Ireland 1998.

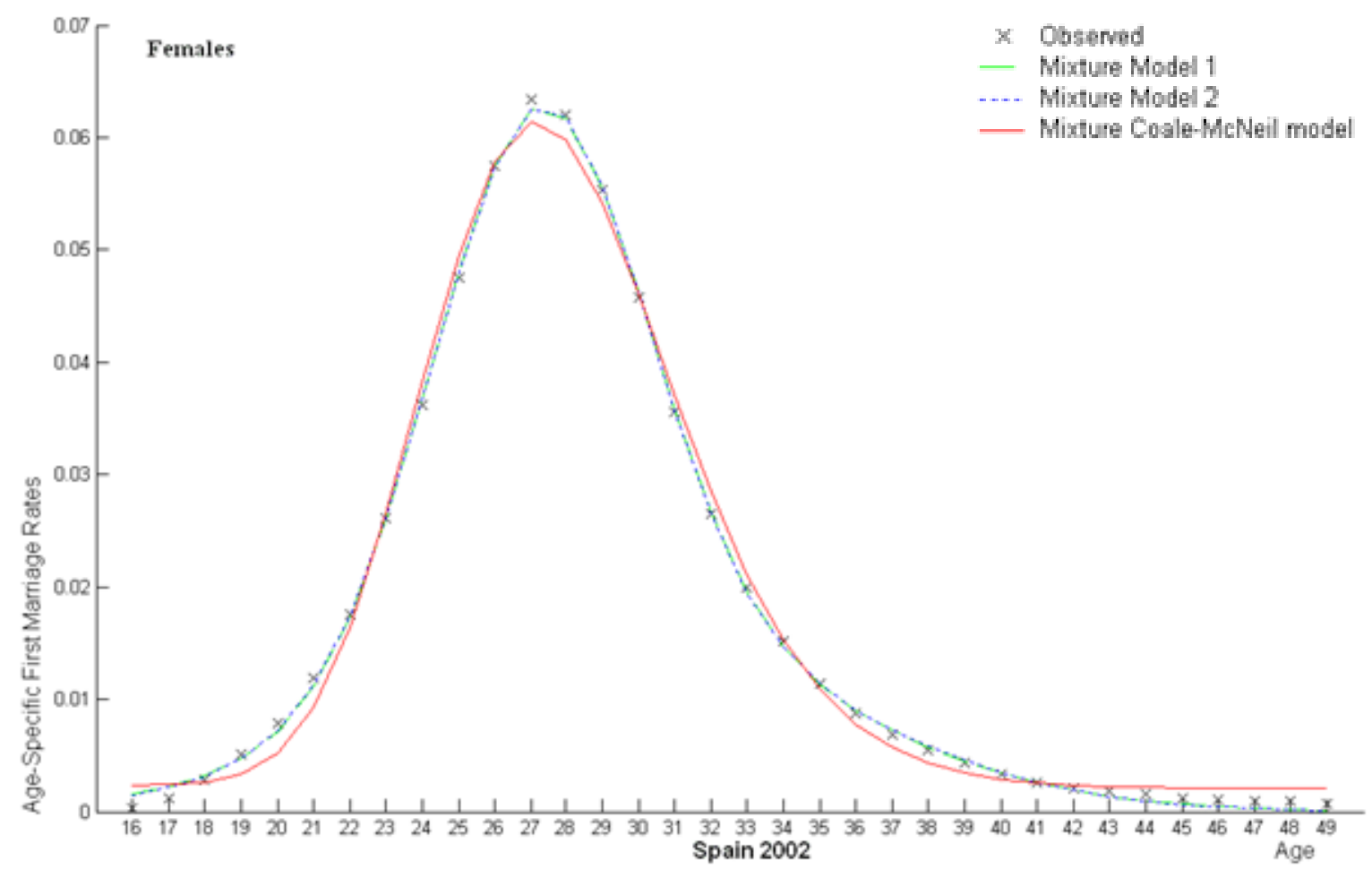

Figure 4. Observed and estimated age-specific first marriage rates of females, using mixture models for Spain 2002. 


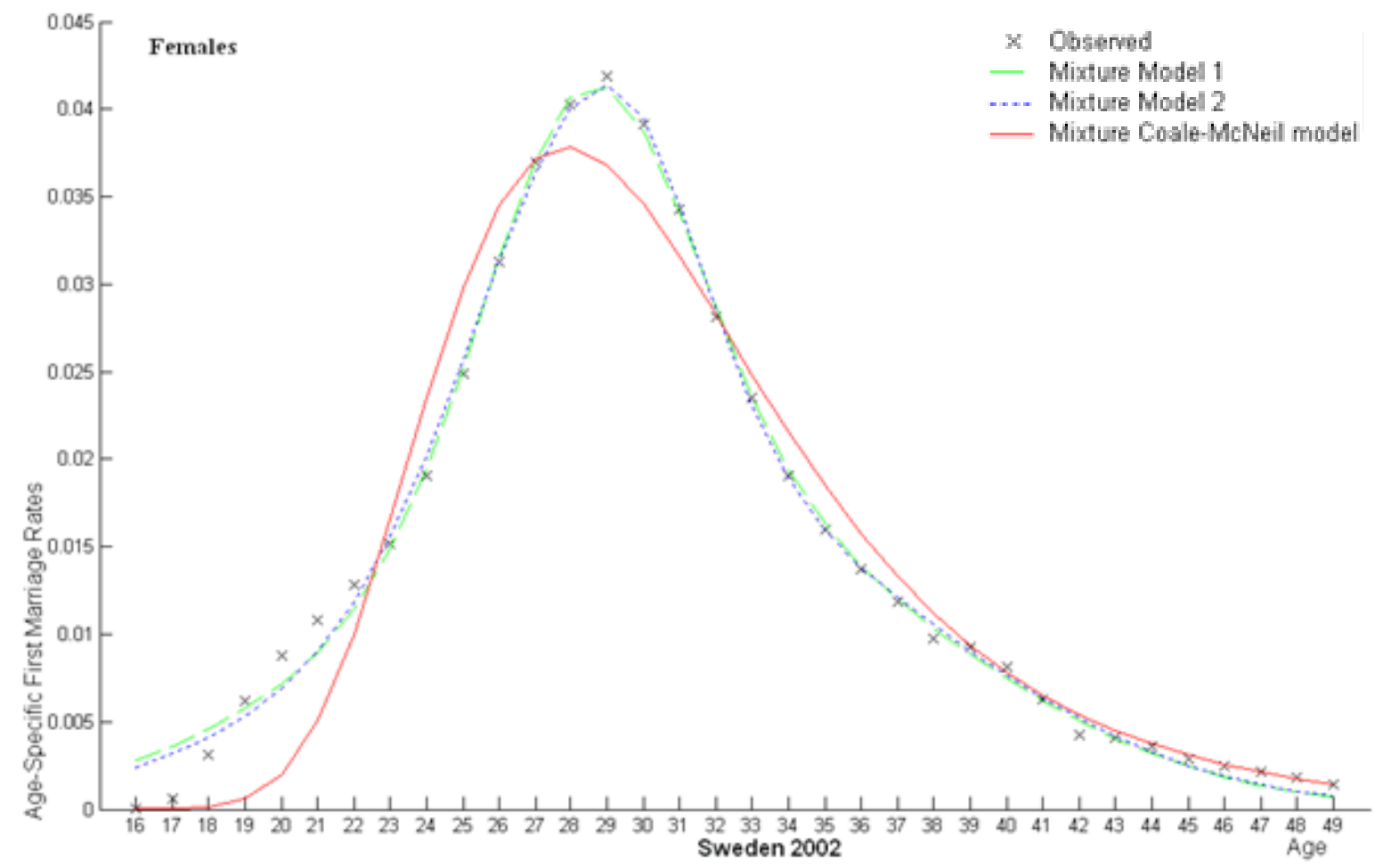

Figure 5. Observed and estimated age-specific first marriage rates of females, using mixture models, for Sweden 2002.

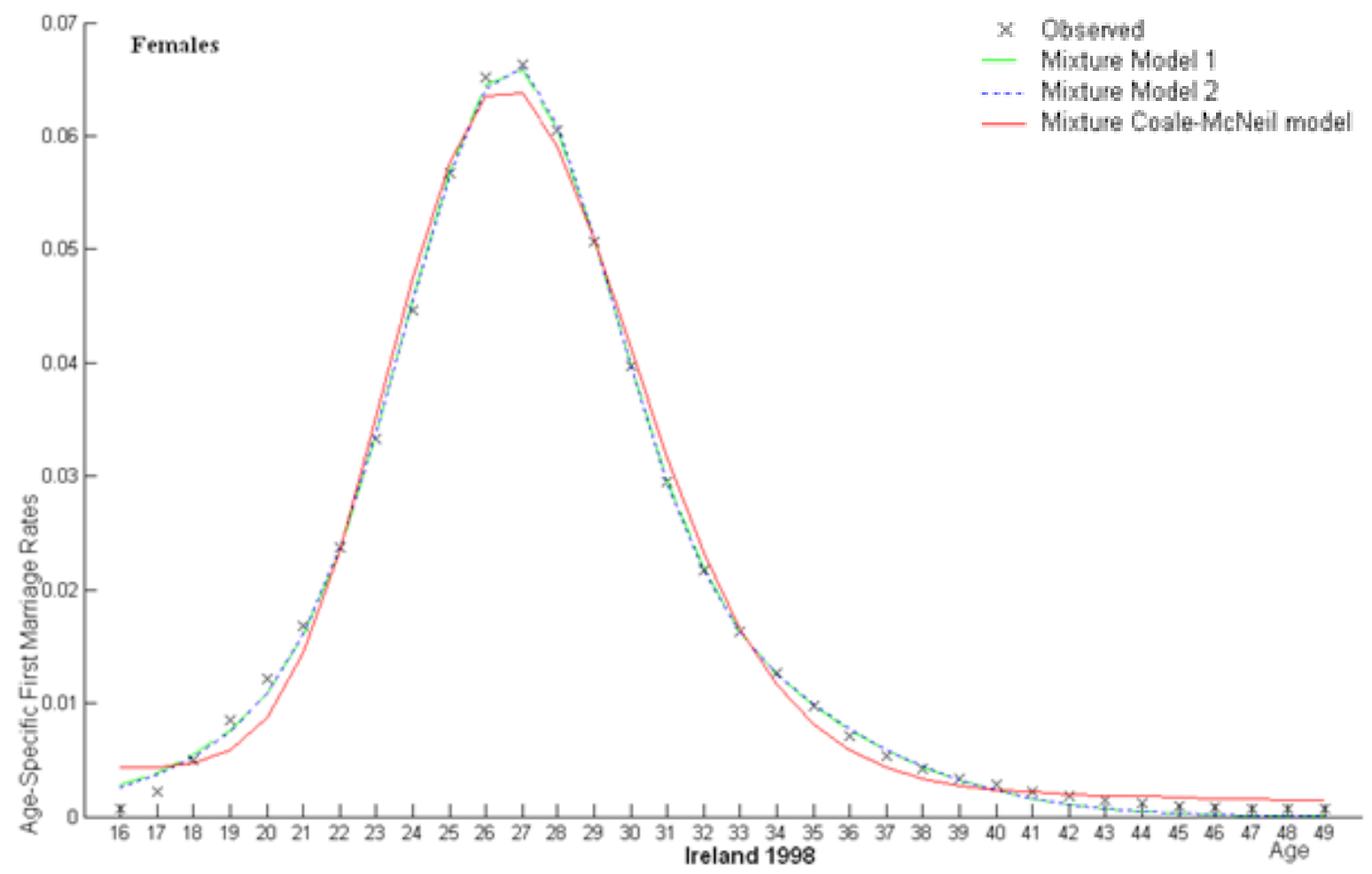

Figure 6. Observed and estimated age-specific first marriage rates of females, using mixture models for Ireland 1998. 